\title{
Pearson Syndrome
}

National Cancer Institute

\section{Source}

National Cancer Institute. Pearson Syndrome. NCI Thesaurus. Code C115326.

The most severe syndrome in the spectrum of single, large-scale mitochondrial DNA (mtDNA) deletions (SLSMDs), usually presenting shortly after birth with sideroblastic anemia. The condition is often associated with exocrine pancreas insufficiency and multisystem dysfunction including diabetes mellitus, cortisol deficiency, hypothyroidism, hypoparathyroidism, and growth hormone deficiency. Commonly associated clinical findings include the following: failure to thrive, hypotonia, ptosis, ophthalmoparesis, and renal disease. 